\title{
Geniposide inhibits high glucose-induced cell adhesion through the NF-KB signaling pathway in human umbilical vein endothelial cells
}

\author{
Guang-fa WANG\#, Shao-yu WU\#, Wei XU, Hong JIN, Zheng-guang ZHU, Zhong-huang LI, Yuan-xin TIAN, Jia-jie ZHANG, \\ Jin-jun RAO*, Shu-guang WU*
}

School of Pharmaceutical Sciences, Southern Medical University, Guangzhou 510515, China

\begin{abstract}
Aim: To investigate whether geniposide, an iridoid glucoside extracted from gardenia jasminoides ellis fruits, inhibits cell adhesion to human umbilical vein endothelial cells (HUVECs) induced by high glucose and its underlying mechanisms.

Methods: HUVECs were isolated from human umbilical cords and cultured. The adhesion of monocytes to HUVECs was determined using fluorescence-labeled monocytes. The mRNA and protein levels of vascular cell adhesion molecule-1 (VCAM-1) and endothelial selectin (E-selectin) were measured using real-time RT-PCR and ELISA. Reactive oxygen species (ROS) production was measured using a fluorescent probe. The amounts of nuclear factor-kappa B (NF-kB) and inhibitory factor of NF-kB (IkB) were determined using Western blot analysis. The translocation of NF-kB from the cytoplasm to the nucleus was determined using immunofluorescence.

Results: Geniposide (10-20 $\mathrm{mol} / \mathrm{L})$ inhibited high glucose (33 mmol/L)-induced adhesion of monocytes to HUVECs in a dose-dependent manner. This compound (5-40 $\mu \mathrm{mol} / \mathrm{L})$ also inhibited high glucose-induced expression of VCAM-1 and E-selectin at the gene and protein levels. Furthermore, geniposide $(5-20 \mu \mathrm{mol} / \mathrm{L})$ decreased ROS production and prevented IkB degradation in the cytoplasm and NF-KB translocation from the cytoplasm to the nucleus in HUVECs.

Conclusion: Geniposide inhibits the adhesion of monocytes to HUVECs and the expression of CAMs induced by high glucose, suggesting that the compound may represent a new treatment for diabetic vascular injury. The mechanism underlying this inhibitory effect may be related to the inhibition of ROS overproduction and NF-KB signaling pathway activation by geniposide.
\end{abstract}

Keywords: high glucose; geniposide; human umbilical vein endothelial cells; cell adhesion molecules; vascular cell adhesion molecule-1; endothelial selectin; nuclear factor-kappa B

Acta Pharmacologica Sinica (2010) 31: 953-962; doi: 10.1038/aps.2010.83

\section{Introduction}

Endothelial dysfunction plays important roles in the pathogenesis of vascular diseases induced by hyperglycemia in diabetes mellitus ${ }^{[1,2]}$. The earliest events in diabetic endothelial dysfunction are the expression of cell adhesion molecules (CAMs) and adhesion of leukocytes to the endothelium ${ }^{[3,4]}$. Under high glucose conditions, endothelial cells increase the expression of CAMs such as vascular cell adhesion molecule-1 (VCAM-1) and endothelial selectin (E-selectin) ${ }^{[3,4]}$. Then, numerous leukocytes adhere to the vascular endothelium, transmigrate the endothelium and aggravate endothelial dysfunction $^{[3,4]}$.

The mechanisms underlying hyperglycemia-induced vascu-

\footnotetext{
\# These authors contributed equally to this paper.

* To whom correspondence should be addressed.

E-mail shuguang@smu.edu.cn (Shu-guang WU); raojj@smu.edu.cn (Jin-jun RAO)

Received 2010-02-07 Accepted 2010-06-04
}

lar injury are not fully understood. Hyperglycemia-induced overproduction of reactive oxygen species (ROS), such as superoxide, the hydroxyl radical and hydrogen peroxide, is recognized as the causal factor responsible for diabetic vascular injury $^{[5-7]}$. ROS increases the adhesiveness of endothelial cells via activation of nuclear factor-kappa B (NF-kB), a transcriptional factor for regulating the expression of genes including $\mathrm{CAMs}^{[8,9]}$. Under normal conditions, NF- $\mathrm{KB}$ is sequestrated in the cytoplasm via binding to inhibitory factor of NF- $\mathrm{KB}(\mathrm{I} \kappa \mathrm{B})$. Once I $\mathrm{KB}$ is degraded, NF- $\mathrm{kB}$ is released from the NF-кB/IкB complex and translocates from the cytoplasm to the nucleus, followed by increasing gene expression of CAMs such as VCAM-1 and E-selectin ${ }^{[10-13]}$. Therefore, inhibition of ROS overproduction and NF-kB signal pathway activation may be useful in preventing diabetic vascular injury.

Geniposide (Gen) is an iridoid glucoside that is extracted from gardenia jasminoides ellis fruits, which have long been used in traditional Chinese medicine ${ }^{[14]}$. In our previous 
study, we found that geniposide exerts hypoglycemic effects in diabetic mice through inhibiting glycogen phosphorylase and glucose-6-phosphatase activities ${ }^{[14]}$. We also found that genipin, the aglycone of geniposide, inhibits endothelial exocytosis in HUVECs by stimulating nitric oxide production ${ }^{[15]}$. However, whether geniposide prevents high glucose-induced vascular injury was not investigated. Thus, we performed experiments to examine the inhibitory effects of geniposide on cell adhesion in HUVECs induced by high glucose and possible mechanisms of anti-vascular injury activity induced by this compound.

\section{Materials and methods Reagents}

Geniposide (Purity: 98\% by HPLC) was purchased from the National Institute for the Control of Pharmaceutical and Biological Products (Beijing, China). 2', 7'-bis-(2-carboxyethyl)-5(and-6)-carboxyfluorescein, acetoxymethylester (BCECF-AM), Reactive Oxygen Species Assay Kit, Nuclear and Cytoplasmic Protein Extraction Kit, Cell Counting Kit-8, BAY 11-7082 (inhibitor of NF-kB), and Cellular NF-kB Translocation Kit were obtained from Beyotime Institute of Biotechnology (Haimen, China). Collagenase, Endothelial Cell Growth Supplement (ECGS) and 3,3',5,5'-tetramethylbenzdine substrate solution (TMB) were purchased from Sigma-Aldrich (St Louis, MO, USA). Endothelial cell basal medium (EBM) and fetal calf serum (FCS) were obtained from Gibco (Grand Island, NY, USA). The two-step MMLV Platinum SYBR Green qPCR SuperMix-UDG kit was obtained from Invitrogen (Invitrogen, CA, USA). Mouse monoclonal antibodies to E-selectin and VCAM-1 were purchased from Santa Cruz (Santa Cruz, CA, USA). Rabbit monoclonal antibodies to NF-кB, ІкB-a, Histone $\mathrm{H} 3$ and $\beta$-actin were purchased from Cell Signaling Technology (Danvers, Massachusetts, USA).

\section{Cell isolation and culture}

Human umbilical cords were collected into phosphatebuffered saline (PBS). HUVECs were isolated from freshly obtained human umbilical cords by collagenase digestion of the interior of the umbilical vein ${ }^{[16-18]}$. The cell suspension was centrifuged at 1000 round per minute for $5 \mathrm{~min}$, and the cell pellet was resuspended in $4 \mathrm{~mL}$ of EBM supplemented with $20 \%$ fetal bovine serum, $100 \mathrm{U} / \mathrm{mL}$ penicillin and $15 \mu \mathrm{g} / \mathrm{mL}$ ECGS. The cells were plated into 6- or 24-well plates and incubated in a humidified incubator at $37^{\circ} \mathrm{C}$ under $5 \% \mathrm{CO}_{2}$.

\section{Cell viability assay}

The HUVECs were seeded at a density of $5 \times 10^{3}$ cells/well in 96-well plates and cultured for $24 \mathrm{~h}$. Then the cells were treated with or without various concentrations of geniposide $(1,5,10,20,40$ and $80 \mu \mathrm{g} / \mathrm{mL})$. After $24 \mathrm{~h}$, cell viability was measured using the Cell Counting Kit- 8 . Ten microliters of the CCK-8 solution was added into each well of the plate. The cells were incubated for $2 \mathrm{~h}$ in the incubator $\left(37^{\circ} \mathrm{C}\right.$ and $5 \% \mathrm{CO}_{2}$ ). The absorbance was measured at $450 \mathrm{~nm}$ using a microplate reader (Bio-Rad). Cell viability in each well was presented as a percentage of the control.

\section{Cell adhesion assay}

Human acute monocytic leukemia THP-1 cells were labeled with $10 \mu \mathrm{mol} / \mathrm{L}$ BCECF-AM in RPMI-1640 medium containing $10 \% \mathrm{FBS}$ at $37^{\circ} \mathrm{C}$ for $30 \mathrm{~min}^{[19]}$. The labeled cells were centrifuged at 1000 round per minute for $5 \mathrm{~min}$, washed three times with PBS, and then resuspended in the medium. HUVECs were treated with low $(5 \mathrm{mmol} / \mathrm{L})$ or high $(33 \mathrm{mmol} / \mathrm{L})$ glucose for $48 \mathrm{~h}$ after geniposide pretreatment, and then the BCECF-AM-labeled THP-1 cells were added to HUVECs in 6-well plates. The cells were co-cultured at $37^{\circ} \mathrm{C}$ for $1 \mathrm{~h}$, and unbound THP-1 cells were washed three times with PBS. BCECF-AM-labeled THP-1 cells bound to HUVECs were observed by fluorescence microscopy (Leica DMIRB, Leica, Germany) and lysed with $50 \mathrm{mmol} / \mathrm{L}$ Tris- $\mathrm{HCl}, \mathrm{pH} 8.0$, containing $0.1 \%$ sodium dodecyl sulfate. The fluorescence of cell lysates was measured using a spectrofluorometer (FP-6200, JASCO, Japan) at excitation and emission wavelengths of 485 $\mathrm{nm}$ and $535 \mathrm{~nm}$, respectively. The number of adherent cells was expressed as fluorescence intensity. The samples were assayed in triplicate.

\section{Measurement of adhesion molecules}

Adhesion molecules including VCAM-1 and E-selectin on the cell surface were measured using cell surface ELISA as previously described $^{[14]}$. Briefly, HUVECs were cultured in 24-well plates until reaching confluence and then pretreated with various concentrations of geniposide for different lengths of time. After incubation with low $(5 \mathrm{mmol} / \mathrm{L})$ or high $(33 \mathrm{mmol} / \mathrm{L})$ glucose for $48 \mathrm{~h}$, cells were fixed for $10 \mathrm{~min}$ with $1 \%$ paraformaldehyde at room temperature. After 3 washes with PBS, the fixed cells were probed with mouse anti-human E-selectin or VCAM-1 antibody for $1 \mathrm{~h}$. The cells were washed and incubated with horseradish peroxidase-conjugated secondary antibody for $1 \mathrm{~h}$. After the cells were washed three times with PBS, TMB was added for $30 \mathrm{~min}$, and then $1 \mathrm{~mol} / \mathrm{L} \mathrm{H}_{2} \mathrm{SO}_{4}$ was added to stop the reaction. Optical density was read in a microplate reader at $450 \mathrm{~nm}$. All assays were performed in triplicate.

\section{Measurement of intracellular ROS production}

ROS production was measured using an oxidation-sensitive fluorescent probe (DCFH-DA) ${ }^{[20-22]}$. DCFH-DA penetrates cells and is hydrolyzed by intracellular esterases to the nonfluorescent DCFH, which can be rapidly oxidized to the highly fluorescent 2,7-dichlorofluorescein (DCF) in the presence of ROS. HUVECs were cultured in 6-well plates until reaching confluence and then pretreated with various concentrations of geniposide for different lengths of time. After incubation with low $(5 \mathrm{mmol} / \mathrm{L})$ or high $(33 \mathrm{mmol} / \mathrm{L})$ glucose for $48 \mathrm{~h}$, cells were washed three times with HBSS (without $\mathrm{Ca}^{2+}$ and $\mathrm{Mg}^{2+}$ ). The cells were lysed with cell lysis buffer (PBS containing 20\% ethanol, $0.1 \%$ Tween 20). After being centrifuged, the supernatant was transferred to measure the intensity of fluorescence (relative fluorescence units) at excitation and emission wave- 
lengths of $485 \mathrm{~nm}$ and $530 \mathrm{~nm}$, respectively, using a spectrofluorometer. All assays were performed in triplicate.

\section{Immunofluorescence microscopy}

Translocation of NF-KB p65 from the cytoplasm to the nucleus was determined using the Cellular NF- $\mathrm{kB}$ Translocation Kit according to manufacturer's instructions ${ }^{[23]}$. Briefly, HUVECs were cultured in 24-well plates until reaching confluence and then pretreated with $20 \mu \mathrm{g} / \mathrm{mL}$ geniposide for $45 \mathrm{~min}$. After incubation with low $(5 \mathrm{mmol} / \mathrm{L})$ or high $(33 \mathrm{mmol} / \mathrm{L}) \mathrm{glu}-$ cose for $3 \mathrm{~h}$, cells were fixed for $10 \mathrm{~min}$ at room temperature. After 3 washes with PBS, the fixed cells were blocked for $1 \mathrm{~h}$ to reduce non-specific binding. Next, cells were probed with the primary NF-KB p65 antibody for $1 \mathrm{~h}$, followed by incubation with cy3-conjugated secondary antibody for $1 \mathrm{~h}$ and with DAPI for 5 min before observation. NF-kB p65 protein and nuclei fluoresce red and blue, respectively, and both components were photographed using a fluorescence microscope.

\section{Real-time RT-PCR}

Total RNA was extracted from HUVECs using TRIzol Reagent according to the manufacturer's instruction. One microgram of total RNA was used for cDNA synthesis with the Two-step MMLV Platinum SYBR Green qPCR SuperMix-UDG kit (Invitrogen) in a volume of $20 \mu \mathrm{L}$ at $37^{\circ} \mathrm{C}$ for $60 \mathrm{~min}$ and $95^{\circ} \mathrm{C}$ for $5 \mathrm{~min}$. Primers were designed using the Primer Express oligo design software (Applied BioSystems, CA, USA) and synthesized by Invitrogen. All primer sets were subjected to rigorous database searches to identify potential conflicting transcript matches to pseudogenes or homologous domains within related genes. The sequences of the real-time PCR primers for GAPDH, VCAM-1 and E-selectin cDNA are listed in Table 1. The SYBR Green I assay was used for detecting the products from the reverse-transcribed cDNA samples. GAPDH was used as the normalizer. PCR reactions for each sample were performed in duplicate, and the relative gene expression was analyzed as described previously.

\section{Preparation of cytoplasmic and nuclear extracts}

Cell cytoplasmic and nuclear extracts were prepared using the Nuclear and Cytoplasmic Protein Extraction Kit according to the manufacturer's instructions ${ }^{[24]}$. Briefly, after cells were

Table 1. PCR primer pairs used to amplify GAPDH, VCAM-1 and E-selectin cDNA fragments.

\begin{tabular}{ccccc}
\hline Target & & Oligonucleotide sequence & $\operatorname{Tm}^{\circ} \mathrm{C}$ & $\begin{array}{r}\text { Predicted } \\
\text { product size }\end{array}$ \\
\hline GAPDH & $\mathrm{F}$ & 5'-TTGTTGCCATCAATGACCCC-3' $^{\prime}$ & 58 & $836 \mathrm{bp}$ \\
& $\mathrm{R}$ & 5'-TGACAAAGTGGTCGTTGAGG-3' $^{\prime}$ & & \\
VCAM-1 & $\mathrm{F}$ & 5'-GCAAGGTTCCTAGCGTGTAC-3' $^{\prime}$ & 58 & $336 \mathrm{bp}$ \\
& $\mathrm{R}$ & 5'-GGCTCAAGCTGTCATATTCAC-3' $^{\prime}$ & & \\
E-selectin & $\mathrm{F}$ & 5'-AACTTCCATGAGGCCAAACG-3' $^{\prime}$ & 58 & $168 \mathrm{bp}$ \\
& $\mathrm{R}$ & 5'-TTGTCGTTGCCAGTGTTCAG-3' $^{\prime}$ & & \\
\hline
\end{tabular}

F, forward primers; $\mathrm{R}$, reverse primer; $\mathrm{Tm}$, melting temperature. washed with ice-cold PBS and collected into pre-chilled centrifuge tubes, cells were centrifuged and resuspended in ice-cold cell lysis buffer (10 mmol/L Hepes, pH 7.9; 10 mmol/L KCl; $0.1 \mathrm{mmol} / \mathrm{L}$ EDTA; $1 \mathrm{mmol} / \mathrm{L}$ DTT, $0.4 \%$ IGEPAL; $2 \mu \mathrm{g} / \mathrm{mL}$ protease inhibitor aprotinin; $1 \mathrm{mmol} / \mathrm{L}$ phenylmethylsulfonyl fluoride (PMSF); $250 \mu \mathrm{g} / \mathrm{mL}$ benzamidine; $2 \mu \mathrm{g} / \mathrm{mL}$ leupeptin). Cell lysates were incubated on ice for $15 \mathrm{~min}$ and centrifuged at 12000 round per minute for $4 \mathrm{~min}$ at $4^{\circ} \mathrm{C}$. Subsequently, nuclear pellets were washed in $500 \mu \mathrm{L}$ of ice-cold cell lysis buffer and resuspended in $150 \mu \mathrm{L}$ of nuclear extraction buffer $(0.4 \mathrm{~mol} / \mathrm{L} \mathrm{NaCl} ; 20 \mathrm{mmol} / \mathrm{L}$ Hepes, $\mathrm{pH} 7.9 ; 1 \mathrm{mmol} / \mathrm{L}$ EDTA; $1 \mathrm{mmol} / \mathrm{L} \mathrm{DTT;} 1 \mathrm{mmol} / \mathrm{L}$ PMSF). After mixing for $30 \mathrm{~min}$ and centrifuging at 12000 round per minute for $4 \mathrm{~min}$ at $4{ }^{\circ} \mathrm{C}$, nuclear extracts in the supernatant were aliquoted and stored at $-70^{\circ} \mathrm{C}$ until use. Cell cytoplasmic and nuclear extracts were quantified using a BCA Protein Assay kit (BPA, Beyotime Institute of Biotechnology).

\section{Protein extraction and Western blot analysis}

Cells were lysed with ice-cold lysis buffer. Cell lysates were centrifuged at 10000 round per minute for $5 \mathrm{~min}$ at $4^{\circ} \mathrm{C}$, and the supernatants were collected. Protein concentrations in the supernatants were measured using the BCA protein assay kit (KangChen Bio-tech Inc, Shanghai, China). Then, $50 \mu \mathrm{g}$ of protein samples was separated on $10 \%$ resolving/ $4 \%$ stacking Tris-HCL gels. Separated proteins were transferred to polyvinylidene difluoride membranes. The membranes were blocked in 5\% BSA in $1 \times$ Tris Buffered Saline, 0.1\% TWEEN20 (TBST) for $1 \mathrm{~h}$ at room temperature. Blocked membranes were immunoblotted with antibodies to NF- $\mathrm{kB}$, IкB-a, Histone $\mathrm{H} 3$ and $\beta$-actin overnight at $4^{\circ} \mathrm{C}$. The membranes were then washed and probed with a horseradish peroxidase-conjugated secondary antibody for $1 \mathrm{~h}$ at room temperature. Chemiluminescence detection was performed with a chemiluminescence detection kit (KangChen Bio-tech Inc) according to the manufacturer's instructions.

\section{Statistical analysis}

Data are expressed as means \pm SEM or means \pm SD. Variables between groups were compared using one-way ANOVA, followed by Student-Newman-Keuls or Dunnett's T3 procedure when the assumption of equal variances did not hold. Twotailed $P$ values $<0.05$ were considered statistically significant. Statistical analyses were conducted with SPSS 13.0.

\section{Results}

Geniposide inhibits THP-1 cell adhesion to HUVECs induced by high glucose concentration

To explore whether geniposide inhibits high glucose-induced inflammatory reactions in HUVECs, the effect of geniposide on adhesion of monocyte to HUVECs was evaluated using fluorescence-labeled monocytes. As shown in Figure 1A and $1 \mathrm{~B}$, after treatment with high glucose for $48 \mathrm{~h}$, adhesion of monocytes to HUVECs significantly increased $(P<0.01 \mathrm{com}-$ pared to normal glucose treatment). Pretreatment of HUVECs with 10 and $20 \mu \mathrm{g} / \mathrm{mL}$ geniposide for $2 \mathrm{~h}$ markedly decreased 

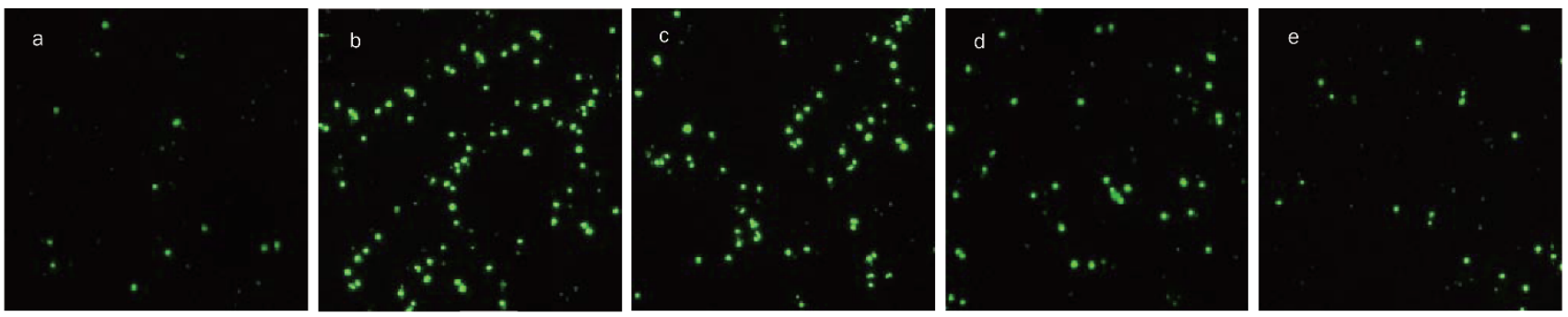

B

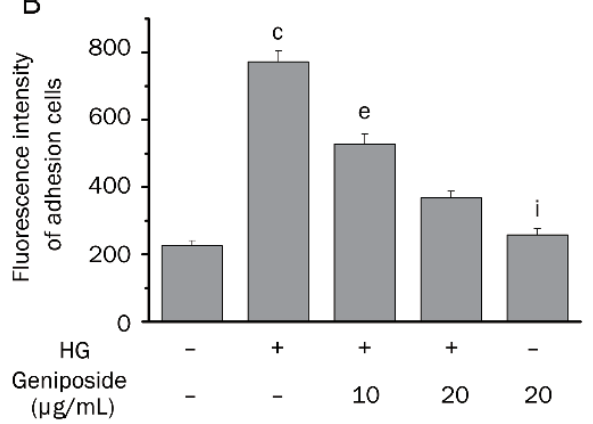

Figure 1. Effect of geniposide on high glucose-induced THP-1 cell adhesion to HUVECs. HUVECs were pretreated with or without geniposide and then induced with high glucose (33 $\mathrm{mmol} / \mathrm{L}$ ) for $48 \mathrm{~h}$. Adhesion of fluorescence-labeled THP-1 cells to HUVECs was determined as described in Materials and methods. Adherent THP-1 cells were photographed $(\times 100)$. (a) Control; (b) High glucose (33 mmol/L); (c) Treatment with $10 \mu \mathrm{g} / \mathrm{mL}$ geniposide for $2 \mathrm{~h}$ and high glucose; (d) Treatment with $20 \mu \mathrm{g} / \mathrm{mL}$ geniposide for $2 \mathrm{~h}$ and high glucose; (e) Treatment with $20 \mu \mathrm{g} / \mathrm{mL}$ geniposide for $2 \mathrm{~h}$ alone; (B) Quantification of adherent cells (fluorescence intensity represented the number of adherent cells). Data are expressed as means \pm SEM of 3 independent experiments. ${ }^{\mathrm{C}} P<0.01$ vs control (Con), ${ }^{e} P<0.05$ vs high glucose (HG), ${ }^{\mathrm{i}} P<0.01$ vs HG. high glucose-induced monocyte adhesion to HUVECs $(P<0.01$ compared to high glucose treatment alone).

Geniposide inhibits the expression of cell adhesion molecules (CAMs) in HUVECs induced by high glucose concentration

Since geniposide could inhibit high glucose-induced cell adhesion, we investigated whether geniposide inhibited the expression of VCAM-1 and E-selectin in HUVECs under high glucose conditions. HUVECs were pretreated with increas- ing concentrations of geniposide for various lengths of time and stimulated with high glucose for $48 \mathrm{~h}$. The expression of VCAM-1 and E-selectin in the HUVECs was measured using cell surface ELISA. As shown in Figure 2A-D, treatment with high glucose $(33 \mathrm{mmol} / \mathrm{L})$ significantly increased the expression of VCAM- 1 and E-selectin in HUVECs $(P<0.01$ compared to normal glucose treatment). However, geniposide inhibited high glucose-induced expression of VCAM-1 and E-selectin in a dose-dependent manner, with a maximal inhibitory effect

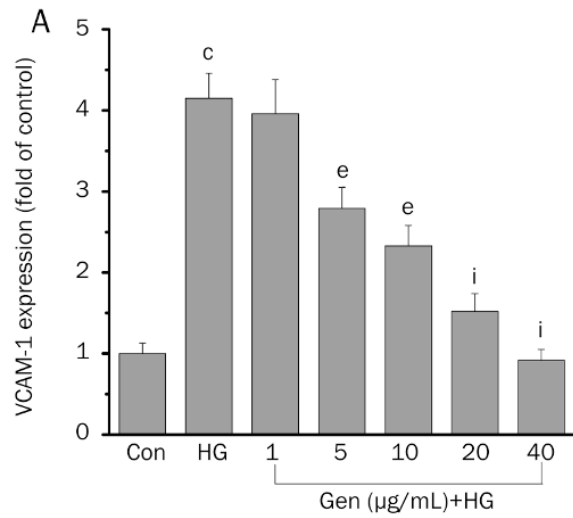

C

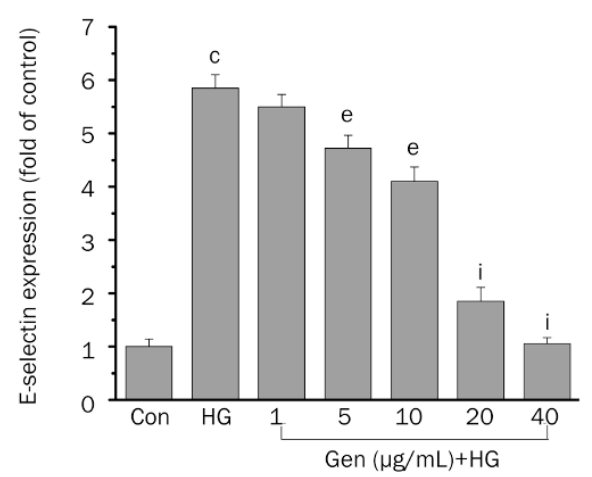

B

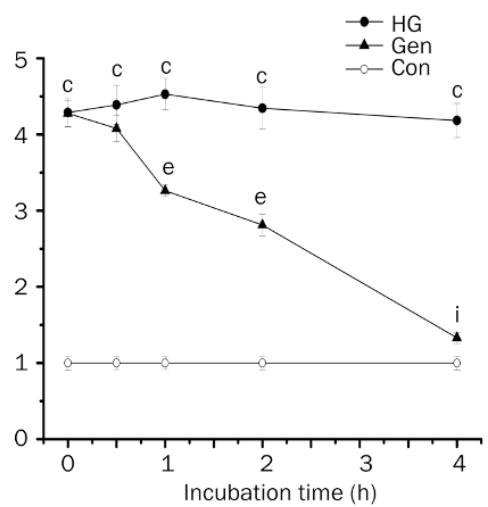

D

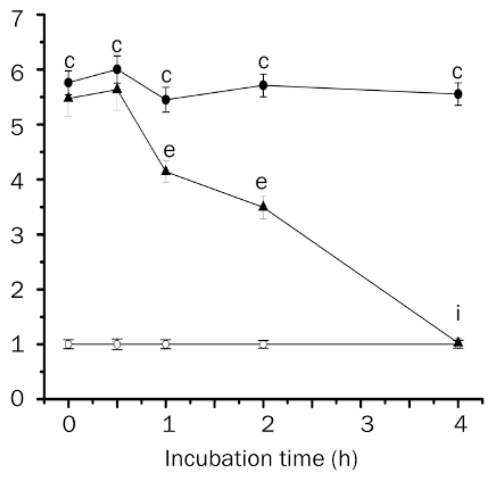

Figure 2. Effect of geniposide on high glucoseinduced VCAM-1 and E-selectin expression in HUVECs. HUVECs were pretreated with or without the indicated concentrations of geniposide for various lengths of time and then cultured with high glucose for $48 \mathrm{~h}$. VCAM-1 and E-selectin expression in HUVECs was measured using cell surface ELISA. (A) Pretreatment with geniposide for $2 \mathrm{~h}$ inhibited VCAM-1 expression in HUVECs in a concentrationdependent manner. (B) Pretreatment with 20 $\mu \mathrm{g} / \mathrm{mL}$ geniposide inhibited VCAM-1 expression in HUVECs in a time-dependent manner. (C) Pretreatment with geniposide for $2 \mathrm{~h}$ inhibited E-selectin expression in HUVECs in a concentrationdependent manner. (D) Pretreatment with $20 \mu \mathrm{g} /$ $\mathrm{mL}$ geniposide inhibited E-selectin expression in HUVECs in a time-dependent manner. Data are expressed as means \pm SEM $(n=3)$ of fold changes compared to control values. ${ }^{\mathrm{c}} P<0.01$ vs control (Con), ${ }^{e} P<0.05$ vs high glucose (HG), ${ }^{i} P<0.01$ vs HG. 
achieved at $40 \mu \mathrm{g} / \mathrm{mL}$ (Figure $2 \mathrm{~A}$ and $2 \mathrm{C}$ ). The significant inhibition caused by geniposide was observed within $1 \mathrm{~h}$ after the start of pretreatment and increased in a time-dependent manner (Figure 2B and 2D).

\section{Geniposide inhibits mRNA expression of CAMs in HUVECs under high glucose concentration}

In order to further clarify the mechanism responsible for the changes in the levels of CAMs, we next examined the effect of geniposide on mRNA expression of VCAM-1 and E-selectin in HUVECs under high glucose conditions. HUVECs were pretreated with increasing concentrations of geniposide for various lengths of time and then cultured with high glucose for $48 \mathrm{~h}$. The expression of VCAM-1 and E-selectin in the HUVECs was evaluated by real-time RT-PCR. As shown in Figure 3A-3D, high glucose significantly increased mRNA expression of VCAM-1 and E-selectin in HUVECs $(P<0.01$ compared to normal glucose treatment). However, geniposide inhibited high glucose-induced mRNA expression of VCAM-1 and E-selectin in a dose-dependent manner, with a maximal inhibitory effect achieved at $40 \mu \mathrm{g} / \mathrm{mL}$ (Figure 3A and 3C). The inhibition caused by geniposide was observed within $1 \mathrm{~h}$ after the start of pretreatment and increased in a time-dependent manner (Figure 3B and 3D). This suggests that geniposide suppresses VCAM-1 and E-selectin expression at the gene level.

\section{Effect of geniposide on HUVEC viability}

We next examined the effect of geniposide on HUVEC viability to determine whether the inhibitory effect of geniposide on expression of VCAM-1 and E-selectin is related to the cytotoxicity induced by this compound. HUVECs were treated with geniposide at concentrations of $1,5,10,20,40$ and $80 \mu \mathrm{g} / \mathrm{mL}$ for $24 \mathrm{~h}$. The results showed that geniposide at the above concentrations had no inhibitory effect on HUVEC viability (Figure 4)

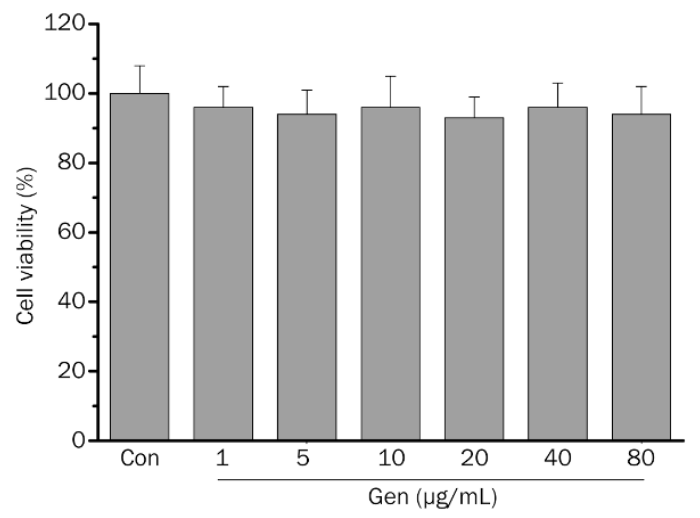

Figure 4. Effect of geniposide on HUVEC viability. HUVECs were treated with geniposide $(1,5,10,20,40$ and $80 \mu \mathrm{g} / \mathrm{mL})$ or vehicle for $24 \mathrm{~h}$. After treatment, cell viability was determined with the Cell Counting Kit-8. Data are expressed as means $\pm \operatorname{SD}(n=3)$.

\section{Geniposide inhibits high glucose-induced ROS overproduction}

To determine whether the effect of geniposide on CAM expression was related to its ability to inhibit ROS production, intracellular ROS generation was measured with a fluorescent probe. As shown in Figure 5A and 5B, exposure to high glucose resulted in a more than 2-fold increase in ROS generation compared to that induced by normal glucose. In contrast, pretreatment with $5-20 \mu \mathrm{g} / \mathrm{mL}$ geniposide significantly
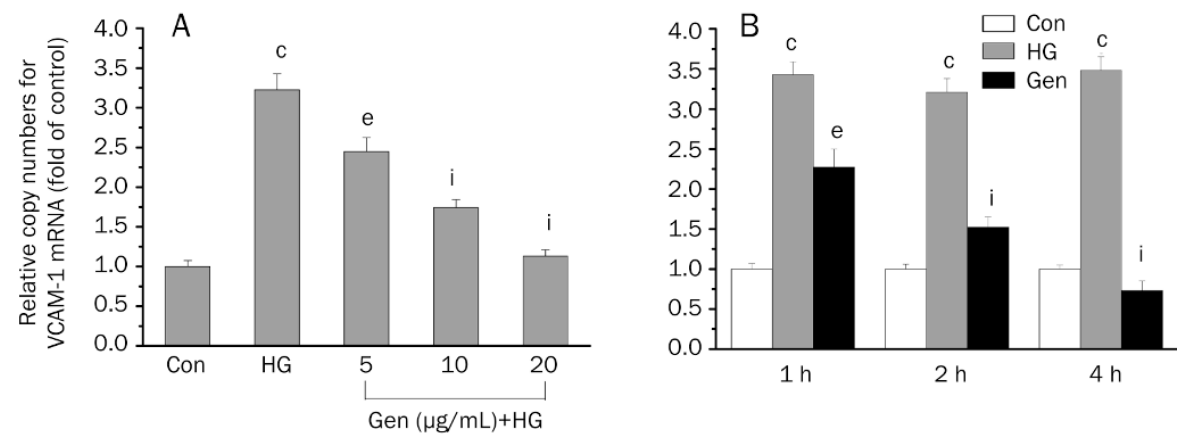

Figure 3. Effect of geniposide on high glucoseinduced VCAM-1 and E-selectin mRNA expression in HUVECs. HUVECs were pretreated with or without the indicated concentrations of geniposide for various lengths of time and then induced with high glucose for $48 \mathrm{~h}$. VCAM-1 and E-selectin mRNA expression in HUVECs was analyzed by real-time RT-PCR. (A) Pretreatment with geniposide for $2 \mathrm{~h}$ inhibited VCAM-1 mRNA expression in HUVECs induced by high glucose in a concentration-dependent manner. (B) Pretreatment with $20 \mu \mathrm{g} / \mathrm{mL}$ geniposide inhibited VCAM-1 mRNA expression in HUVECs
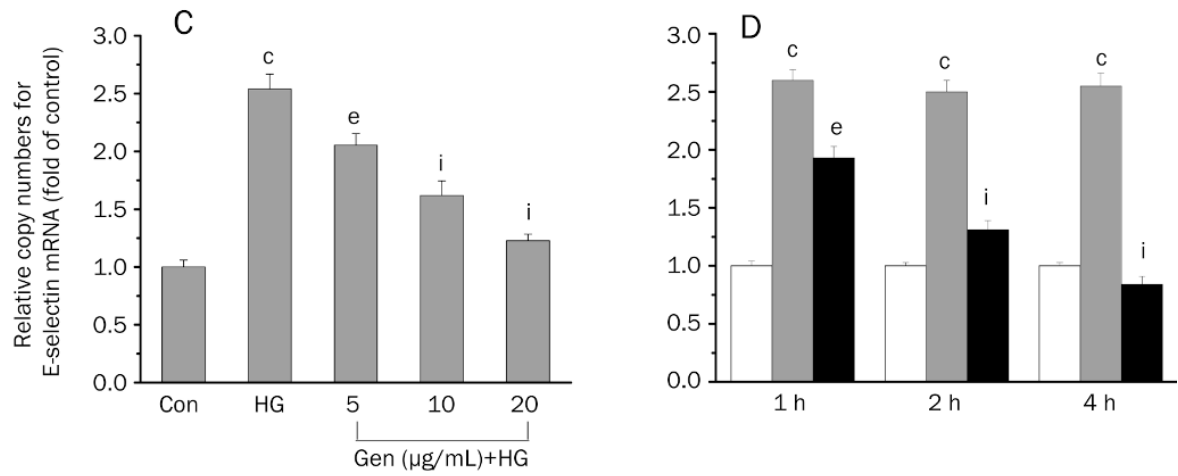
induced by high glucose in a time-dependent manner. (C) Pretreatment with geniposide for $2 \mathrm{~h}$ inhibited E-selectin mRNA expression in HUVECs induced by high glucose in a concentration-dependent manner. (D) Pretreatment with $20 \mu \mathrm{g} / \mathrm{mL}$ geniposide inhibited E-selectin mRNA expression in HUVECs induced by high glucose in a time-dependent manner. Data are expressed as means \pm SEM $(n=3)$ of fold changes compared to control values. ${ }^{c} P<0.01$ vs control (Con), ${ }^{e} P<0.05$ vs high glucose (HG), ${ }^{i} P<0.01$ vs HG. 
decreased high glucose-induced ROS production compared to that induced by high glucose treatment alone (Figure 5A). In addition, the inhibitory effect of geniposide on high glucoseinduced ROS production was observed after pretreatment with $20 \mu \mathrm{g} / \mathrm{mL}$ geniposide for $1 \mathrm{~h}$ and increased in a timedependent manner (Figure 5B).
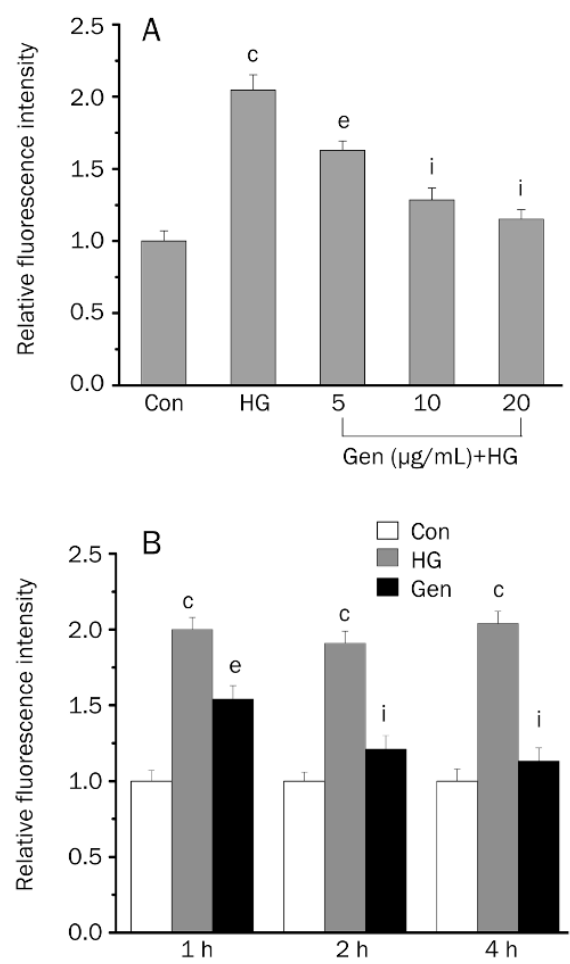

Figure 5. Effect of geniposide on high glucose-induced ROS production in HUVECs. HUVECs were pretreated with or without the indicated concentrations of geniposide for various lengths of time and then induced with high glucose for $48 \mathrm{~h}$. High glucose-induced ROS production in HUVECs was measured with an oxidation-sensitive fluorescent probe (DCFH-DA). (A) Pretreatment with geniposide for $2 \mathrm{~h}$ inhibited high glucose-induced ROS production in HUVECs in a concentration-dependent manner. (B) Pretreatment with $20 \mu \mathrm{g} / \mathrm{mL}$ geniposide inhibited high glucose-induced ROS production in HUVECs in a time-dependent manner. Data are expressed as means \pm SD $(n=3)$ of fold changes compared to control values. ${ }^{c} P<0.01$ vs control (Con), ${ }^{e} P<0.05$ vs high glucose (HG), i $P<0.01$ vs HG.

\section{Geniposide inhibits high-glucose-induced NF-KB signaling pathway activation}

In this study, we explored the effect of geniposide on high glucose-induced NF-kB signaling pathway activation using Western blotting and immunocytochemistry. As shown in Figure $6 \mathrm{~A}$, high glucose significantly increased NF-kB p65 expression by about 3-fold in nuclear extracts compared to that induced by normal glucose. In contrast, pretreatment with 5,10 , or $20 \mu \mathrm{g} / \mathrm{mL}$ geniposide for $1 \mathrm{~h}$ markedly inhibited high glucoseinduced nuclear NF-kB p65 expression in a dose-dependent manner (Figure 6A). Furthermore, high glucose significantly decreased IкB- $\alpha$ expression levels in the cytoplasm. However, pretreatment with 5,10 , or $20 \mu \mathrm{g} / \mathrm{mL}$ geniposide for $1 \mathrm{~h}$ markedly inhibited the high glucose-induced decrease in IKB- $\alpha$ expression in a dose-dependent manner (Figure 6B).

To confirm the Western blotting result, we observed the translocation of NF-kB p65 using immuocytochemistry. As
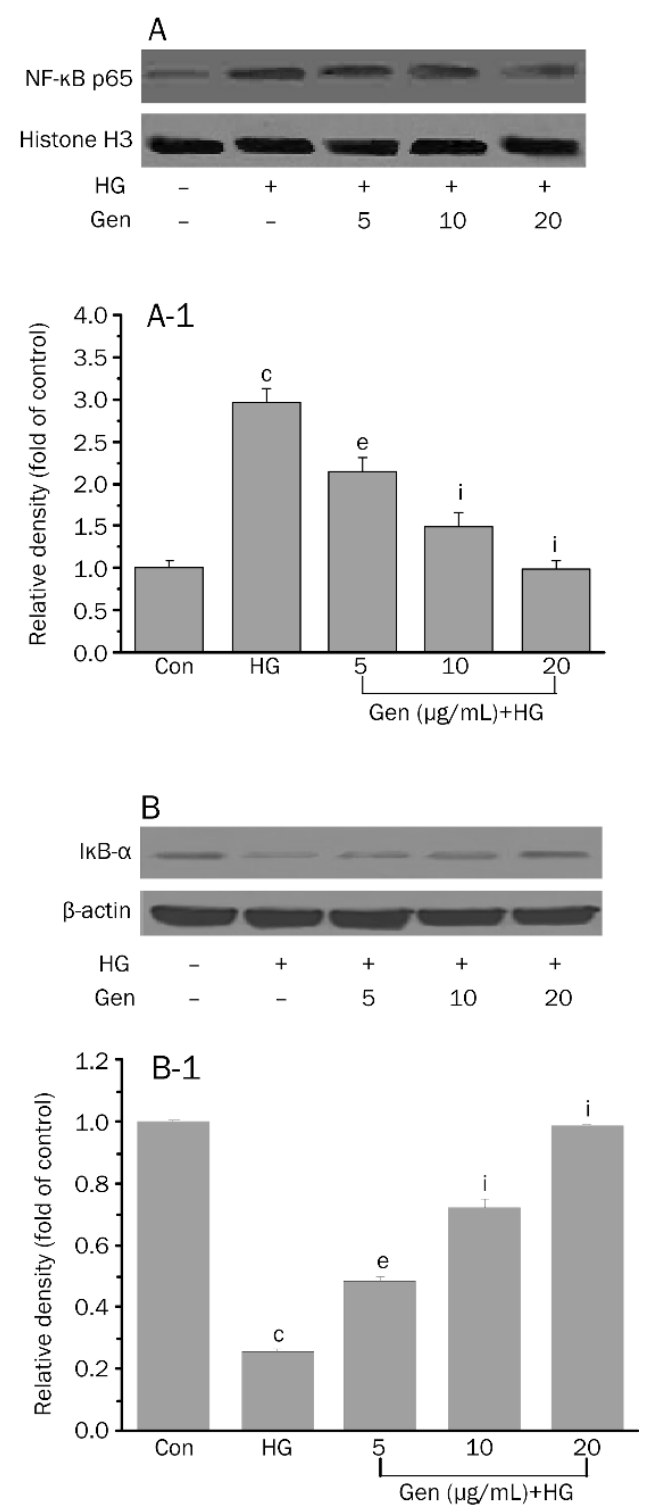

Figure 6. Effect of geniposide on high glucose-induced NF-KB activation. HUVECs were pretreated with or without the indicated concentrations of geniposide for $1 \mathrm{~h}$ and then induced with high glucose for $48 \mathrm{~h}$. Cell cytoplasmic and nuclear extracts were prepared, electrophoresed and separated. Protein levels of NF-KB p65 in nuclear extracts and IKB in cytoplasmic extracts were detected using Western blot analysis. (A) Representative Western blots of NF-KB p65 in nuclear extracts for the indicated concentrations of geniposide pretreatment. (B) Representative Western blots of IKB in cytoplasmic extracts for the indicated concentrations of geniposide pretreatment. (A-1) Semiquantitative analysis of NF-KB p65 in nuclear extracts. (B-1) Semiquantitative analysis of IKB in cytoplasmic extracts. Data are expressed as means \pm SEM $(n=3)$ of fold changes compared to control values. ${ }^{\mathrm{C}} P<0.01$ vs control (Con), ${ }^{\mathrm{e}} P<0.05$ vs high glucose $(\mathrm{HG}),{ }^{\mathrm{i}} P<0.01$ vs $\mathrm{HG}$. 
shown in Figure 7B, high glucose caused greater NF-кB p65 translocation into the nucleus compared to that induced by normal glucose. However, pretreatment with $20 \mu \mathrm{g} / \mathrm{mL}$ geniposide inhibited the translocation of NF-kB p65 from the cytoplasm to the nucleus (Figure 7C). These results were consistent with the results of Western blotting.
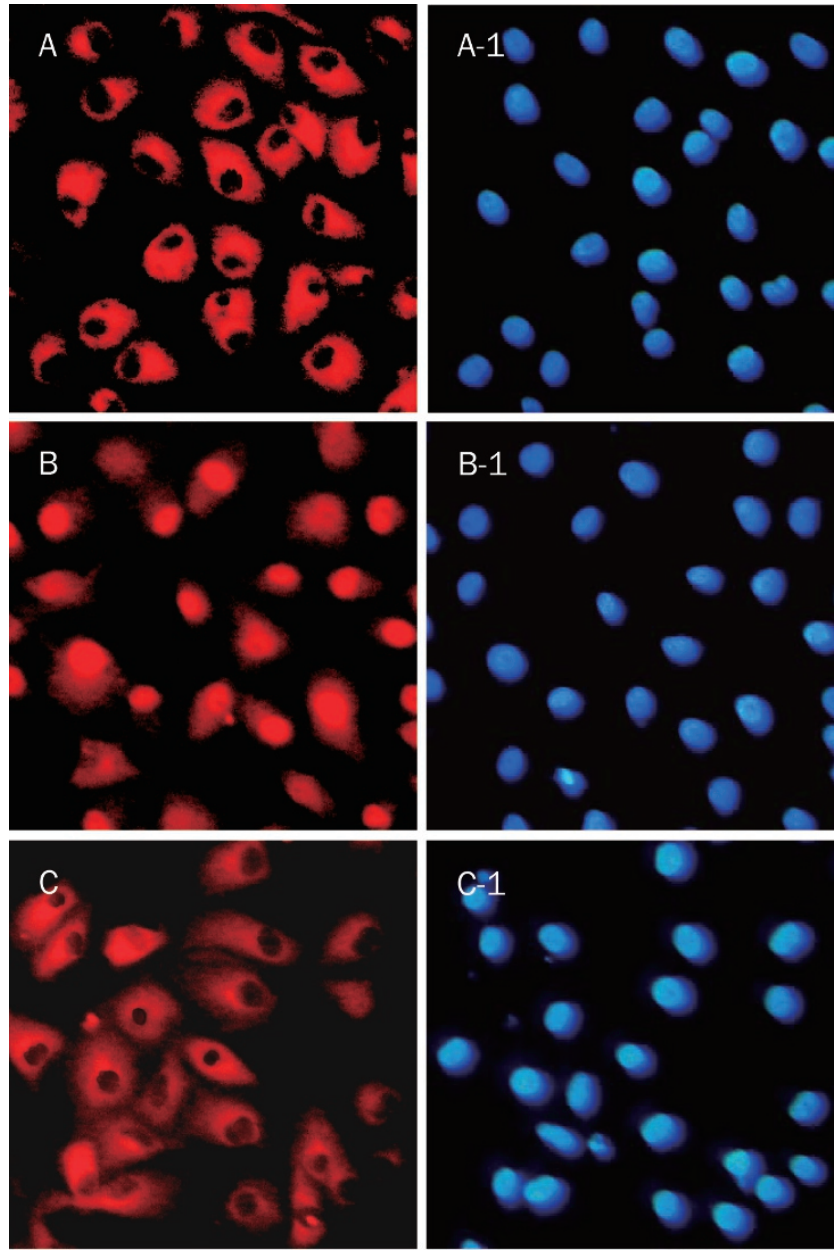

Figure 7. Effect of geniposide on high glucose-induced nuclear translocation of NF-KB p65 in HUVECs. HUVECs were pretreated with $20 \mu \mathrm{g} / \mathrm{mL}$ geniposide for $1 \mathrm{~h}$ and then were induced with high glucose for $12 \mathrm{~h}$. The cells were fixed and labeled with two fluorescent probes. The results were observed by fluorescent microscopy, where NF-KB p65 appears red and the nucleus appears blue $(\times 400)$. (A) NF-KB p65 stains in HUVECs under normal glucose conditions. (A-1) Nuclear stains in HUVECs under normal glucose conditions. (B) NF-KB p65 stains in HUVECs under high glucose conditions. (B-1) Nuclear stains in HUVECs under high glucose conditions. (C) NF-kB p65 stains in HUVECs pretreated with $20 \mu \mathrm{g} / \mathrm{mL}$ geniposide under high glucose conditions. (C-1) Nuclear stains in HUVECs pretreated with $20 \mu \mathrm{g} / \mathrm{mL}$ geniposide under high glucose conditions.

Furthermore, we compared the inhibition ratio of geniposide and an NF- $\mathrm{kB}$ inhibitor, BAY 11-7082, on NF- $\mathrm{kB}$ activation and VCAM-1 expression in HUVECs under high glucose conditions. The cells were pretreated with $20 \mu \mathrm{g} / \mathrm{mL}$ geniposide or $4 \mu \mathrm{g} / \mathrm{mL}$ BAY $11-7082$ for $1 \mathrm{~h}$ or $3 \mathrm{~h}$ and then incubated with $33 \mathrm{mmol} / \mathrm{L}$ glucose for $48 \mathrm{~h}$. The proteins were extracted and the levels of IкB- $\alpha$ and VCAM-1 were analyzed by Western blot. As shown in Figure 8, treatment with geniposide and BAY 11-7082 for $1 \mathrm{~h}$ or $3 \mathrm{~h}$ could completely reverse the high glucose-induced decrease in IкB-a levels. However, more potent inhibition of high glucose-induced VCAM-1 expression was observed with a 3-h treatment with either compound compared to the 1-h treatment (Figure 8). In addition, geniposide had the same inhibition ratio on high glucose-induced NF-kB activation and VCAM-1 expression as BAY 11-7082 (Figure 8)
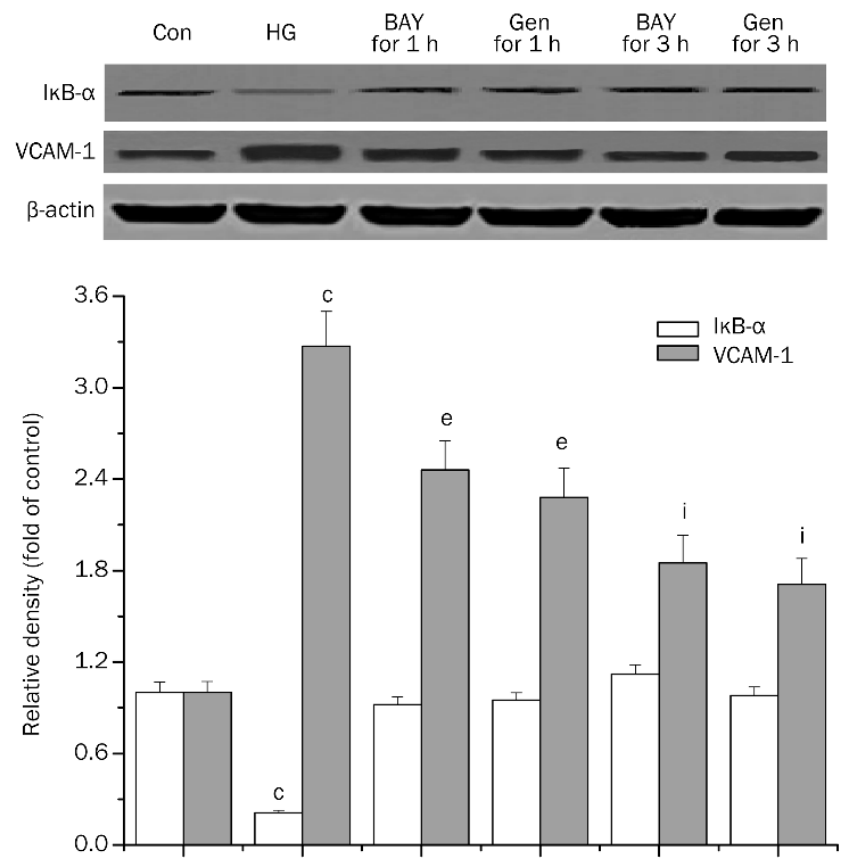

Figure 8. The inhibitory effect of geniposide and NF-KB inhibitor BAY 117082 on NF-KB activation and VCAM-1 expression in HUVECs under high glucose conditions. HUVECs were pretreated with $4 \mu \mathrm{g} / \mathrm{mL}$ BAY 11-7082 or $20 \mu \mathrm{g} / \mathrm{mL}$ geniposide for 1 or $3 \mathrm{~h}$ and then incubated with $33 \mathrm{mmol} / \mathrm{L}$ glucose for $48 \mathrm{~h}$. The proteins were then extracted, and the levels of IKB- $\alpha$ and VCAM-1 were analyzed by Western blot. Data are expressed as means \pm SEM $(n=3)$ of fold changes compared to control values. ${ }^{c} P<0.01$ vs control (Con), ${ }^{e} P<0.05$ vs high glucose (HG), ${ }^{i} P<0.01$ vs HG.

\section{Discussion}

In this study, we found that geniposide inhibits cell adhesion, expression of CAMs, ROS overproduction and NF-kB signal pathway activation in HUVECs under high glucose conditions. To our knowledge, this is the first report of an inhibitory effect of geniposide on high glucose-induced cell adhesion and vascular injury.

In our study, incubation of HUVECs with high glucose significantly increased monocyte adhesion to endothelial cells and the expression of VCAM-1 and E-selectin. The results were consistent with those of previous studies ${ }^{[25]}$. We also found that geniposide significantly inhibited monocyte- 
endothelial cell adhesion and decreased the expression of the two adhesion molecules at the gene and protein levels. In the presence of geniposide, CAM expression in endothelial cells decreased, which in turn attenuated adhesion of circulating leukocytes onto endothelium surfaces and improved endothelial function. Accordingly, CAMs are regarded as potential targets for therapeutic intervention in the process of vascular injury ${ }^{[26]}$. Some agents that can interfere with VCAM-1, P-selectin and E-selectin expression in endothelial cells have shown to be effective in treating diabetic vascular injury ${ }^{[26]}$. Our findings suggest that geniposide may represent a novel agent for blocking adhesion of leukocytes to endothelial cells through interfering with CAM expression.

In this study, we were interested in the determining the mechanism by which geniposide inhibits endothelial cell adhesion in the presence of high glucose. Since previous studies have shown that geniposide possesses in vitro antioxidant activity under oxidative stress induced by hydrogen peroxide ${ }^{[27,28]}$, we first investigated whether geniposide inhibited high glucose-induced ROS overproduction. In our study, exposure of endothelial cells to high glucose resulted in increased levels of intracellular ROS. However, this overproduction was prevented by pretreatment with $5-20 \mu \mathrm{g} / \mathrm{mL}$ geniposide for $2 \mathrm{~h}$. Our results suggest that the inhibitory effects of geniposide on cell adhesion may be related to its anti-oxidative activity.

Then, we investigated the relationship between geniposideinduced cell adhesion inhibition and NF-KB signal pathway activation. NF- $\mathrm{kB}$ regulates the expression of many important genes related to cell adhesion such as VCAM-1 and E-selectin. These two genes have putative binding sites for NF-kB in their promoter regions for activation of gene expression ${ }^{[29-33]}$. Therefore, we hypothesized that inhibition of cell adhesion by geniposide may be related to inhibition of the NF-kB signal pathway. Our study showed that high glucose treatment induced cytoplasmic IкB degradation and NF- $\mathrm{\kappa B}$ translocation from the cytoplasm to the nucleus. In contrast, pretreatment with geniposide prevented cytoplasmic IKB degradation and NF- $\mathrm{kB}$ translocation from the cytoplasm to the nucleus in a dose-dependent manner. Our results suggest that the inhibitory effect of geniposide on cell adhesion may be related to inhibition of the NF-kB signal pathway. More recently, Liu et al reported that geniposide inhibits interleukin-6 and interleukin-8 production in lipopolysaccharide-induced HUVECs by blocking p38 and ERK1/2 signaling pathways ${ }^{[34]}$. In addition to ROS and the NF- $\mathrm{KB}$ pathway, extracellular regulated protein kinase (ERK), C-jun N-terminal kinase (JNK) and p38, the main members of mitogen-activated protein kinase (MAPK) family, may also be involved in high glucose-induced VCAM-1 and E-selectin expression. Accumulated evidence has demonstrated that endothelial damage induced by high glucose can alter cellular functions via activation of ERK1/2, JNK, and $\mathrm{p} 38^{[35,36]}$. In fact, a recent study has shown that geniposide protects PC12 cells from oxidative damage via upregulated phosphorylation of ERK1/2 ${ }^{[37]}$. Furthermore, penta-acetyl geniposide, the derivative of geniposide, induced apoptosis via ERK-, p38- and JNK-mediated AP-1 activation in C6 glioma cells ${ }^{[38]}$. Taken together, the JNK, p38 and ERK1/2 pathways may also be involved in the inhibitory effect of geniposide on high glucose-induced VCAM-1 and E-selectin expression and monocyte adhesion.

In our study, NF-kB pathway inhibition could be rapidly induced by geniposide pretreatment for $1 \mathrm{~h}$. Our results are consistent with those in other studies. For example, Lee et al reported that pretreatment with an aqueous extract of Buddleja officinalis (ABO) for 30 min suppressed high-glucose-induced vascular inflammatory processes by inhibiting NF- $\mathrm{KB}$ activation in HUVECs ${ }^{[25]}$, demonstrating that the NF-KB pathway can be rapidly inhibited by small natural compounds. However, it should be noted that complete inhibition of NF-kB activation occurred with 1-h geniposide treatment, whereas maximal inhibition of VCAM-1 and E-selectin expression and ROS generation was observed $4 \mathrm{~h}$ after drug exposure. This fact suggests that there is a time lag from the activation of NF- $\mathrm{KB}$ to the subsequent response of particular genes. This phenomenon has also been observed by other research groups. For example, Shimada et al reported that maximal NF-kB activity was observed at $30 \mathrm{~min}$ and sustained for $2 \mathrm{~h}$ in human umbilical vein endothelial cells (HUVECs) after treatment with lysophosphatidic acid, a proinflammatory lysophospholipid, but the expression VCAM-1 and ICAM-1 was delayed, peaking at $4 \mathrm{~h}$ and remaining for up to $8 \mathrm{~h}$ post-drug treatment ${ }^{[39]}$. In another report, Manna et al observed that NF-KB activation induced by tumor necrosis factor (TNF) can be observed 15 min after stimulation, whereas the earliest time reactive oxygen intermediate (ROI) generation was observed was $1 \mathrm{~h}$ poststimulation $^{[40]}$. Our study also showed that geniposide had the same inhibition ratio of high glucose-induced NF-KB activation and VCAM-1 expression as the NF-kB inhibitor BAY 11-7082. However, the mechanism by which geniposide-mediated peak inhibition of NF-kB activation occurred $3 \mathrm{~h}$ prior to peak suppression of CAM expression and ROS generation remains unclear. It cannot be ruled out whether geniposide may have directly modified VCAM-1 and E-selectin expression or if other unknown mechanisms are involved in this complicated process.

In conclusion, the present study demonstrates that geniposide inhibits high glucose-induced cell adhesion and the expression of VCAM-1 and E-selectin in HUVECs. The mechanism underlying the inhibitory effects of this compound on cell adhesion and adhesion molecule expression may occur through inhibition of ROS overproduction and NF-kB signal pathway activation. Our findings suggest that geniposide, a novel cell adhesion inhibitor, may be used as a preventive agent for diabetic vascular injury.

\section{Acknowledgements}

This work was supported by grants from the Science and Technology Bureau of Guangzhou (2006Z1-E6021), the National Natural Science Foundation of China (No 30901989), and the Natural Science Foundation of Guangdong Province (№ 9151063201000008). 


\section{Author contribution}

Guang-fa WANG, Jin-jun RAO and Shu-guang WU designed the research study; Guang-fa WANG, Shao-yu WU, Jia-jie ZHANG, Wei XU, Yuan-xin TIAN and Hong JIN performed the research and analyzed the data; Zheng-guang ZHU and Zhong-huang LI contributed new analytical reagents and tools; and Guang-fa WANG, Jin-jun RAO and Shu-guang WU wrote the paper.

\section{References}

1 Potenza MA, Gagliardi S, Nacci C, Carratu' MR, Montagnani M. Endothelial dysfunction in diabetes: from mechanisms to therapeutic targets. Curr Med Chem 2009; 16: 94-112.

2 Woodman RJ, Chew GT, Watts GF. Mechanisms, significance and treatment of vascular dysfunction in type 2 diabetes mellitus: focus on lipid-regulating therapy. Drugs 2005; 65: 31-74.

3 Hadi HA, Suwaidi JA. Endothelial dysfunction in diabetes mellitus. Vasc Health Risk Manag 2007; 3: 853-76.

$4 \mathrm{Xu} \mathrm{J}$, Zou MH. Molecular insights and therapeutic targets for diabetic endothelial dysfunction. Circulation 2009; 120: 1266-86.

5 Nishikawa T, Edelstein D, Du XL, Yamagishi S, Matsumura T, Kaneda Y, et al. Normalizing mitochondrial superoxide production blocks three pathways of hyperglycaemic damage. Nature 2000; 404: 787-90.

6 Son SM, Whalin MK, Harrison DG, Taylor WR, Griendling KK. Oxidative stress and diabetic vascular complications. Curr Diab Rep 2004; 4: 247-52.

7 Brownlee M. Biochemistry and molecular cell biology of diabetic complications. Nature 2001; 414: 813-20.

8 Nishikawa T, Edelstein D, Brownlee M. The missing link: a single unifying mechanism for diabetic complications. Kidney Int Suppl 2000; 77: S26-30.

9 Ceriello A. New insights on oxidative stress and diabetic complications may lead to a "causal" antioxidant therapy. Diabetes Care 2003; 26: 1589-96.

10 Collins T. Endothelial nuclear factor-kappa B and the initiation of the atherosclerotic lesion. Lab Invest 1993; 68: 499-508.

11 Collins T, Read MA, Neish AS, Whitley MZ, Thanos D, Maniatis T. Transcriptional regulation of endothelial cell adhesion molecules: NF-kappa B and cytokine-inducible enhancers. FASEB J 1995; 9: 899-909.

12 Schindler U, Baichwal VR. Three NF-kappa B binding sites in the human E-selectin gene required for maximal tumor necrosis factor alpha-induced expression. Mol Cell Biol 1994; 14: 5820-31.

13 De Martin R, Hoeth M, Hofer-Warbinek R, Schmid JA. The transcription factor NF-kappa B and the regulation of vascular cell function. Arterioscler Thromb Vasc Biol 2000; 20: E83-88.

14 Wu SY, Wang GF, Liu ZQ, Rao JJ, Lu L, Xu W, et al. Effect of geniposide, a hypoglycemic glucoside, on hepatic regulating enzymes in diabetic mice induced by a high-fat diet and streptozotocin. Acta Pharmacol Sin 2009; 30: 202-8.

15 Wang GF, Wu SY, Rao JJ, Lu L, Xu W, Pang JX, et al. Genipin inhibits endothelial exocytosis via nitric oxide in cultured human umbilical vein endothelial cells. Acta Pharmacol Sin 2009; 30: 589-96.

16 Jaffe EA, Nachman RL, Becker CG, Minick CR. Culture of human endothelial cells derived from umbilical veins. Identification by morphologic and immunologic criteria. J Clin Invest 1973; 52: 274556.

17 Pan YM, Yao YZ, Zhu ZH, Sun XT, Qiu YD, Ding YT. Caveolin-1 is important for nitric oxide-mediated angiogenesis in fibrin gels with human umbilical vein endothelial cells. Acta Pharmacol Sin 2006; 27:
1567-74.

18 Yao K, Xu B, Liu YP, Ferro A. Effects of beta-adrenoceptor stimulation on endothelial nitric-oxide synthase phosphorylation of human umbilical vein endothelial cells. Acta Pharmacol Sin 2003; 24: 21924.

19 Yamakuchi M, Bao C, Ferlito M, Lowenstein CJ. Epigallocatechin gallate inhibits endothelial exocytosis. Biol Chem 2008; 389: 93541.

20 Li JJ, Tang Q, Li Y, Hu BR, Ming ZY, Fu Q, et al. Role of oxidative stress in the apoptosis of hepatocellular carcinoma induced by combination of arsenic trioxide and ascorbic acid. Acta Pharmacol Sin 2006; 27: 1078-84.

21 Zha RP, Xu W, Wang WY, Dong L, Wang YP. Prevention of lipopolysaccharide-induced injury by 3,5-dicaffeoylquinic acid in endothelial cells. Acta Pharmacol Sin 2007; 28: 1143-8.

22 Zhao Y, Lu N, Li H, Zhang Y, Gao Z, Gong Y. High glucose induced human umbilical vein endothelial cell injury: involvement of protein tyrosine nitration. Mol Cell Biochem 2008; 311: 19-29.

23 Xu Z, Lin S, Wu W, Tan H, Wang Z, Cheng C, et al. Ghrelin prevents doxorubicin-induced cardiotoxicity through TNF-alpha/NF-kappaB pathways and mitochondrial protective mechanisms. Toxicology 2008; 247: 133-8.

24 Lu J, Zhang F, Zhao D, Hong L, Min J, Zhang L, et al. ATRAinhibited proliferation in glioma cells is associated with subcellular redistribution of beta-catenin via up-regulation of Axin. J Neurooncol 2008; 87: 271-7.

25 Lee YJ, Kang DG, Kim JS, Lee HS. Effect of Buddleja officinalis on high-glucose-induced vascular inflammation in human umbilical vein endothelial cells. Exp Biol Med (Maywood) 2008; 233: 694-700.

26 Lutters BC, Leeuwenburgh MA, Appeldoorn CC, Molenaar TJ, Van Berkel TJ, Biessen EA. Blocking endothelial adhesion molecules: a potential therapeutic strategy to combat atherogenesis. Curr Opin Lipidol 2004; 15: 545-52.

27 Liu J, Yin F, Zheng X, Jing J, Hu Y. Geniposide, a novel agonist for GLP-1 receptor, prevents PC12 cells from oxidative damage via MAP kinase pathway. Neurochem Int 2007; 51: 361-9.

28 Liu JH, Yin F, Guo LX, Deng XH, Hu YH. Neuroprotection of geniposide against hydrogen peroxide induced $\mathrm{PC} 12$ cells injury: involvement of PI3 kinase signal pathway. Acta Pharmacol Sin 2009; 30: 159-65.

29 Hooft vHR, Pescini R, DeLamarter JF. Two distinct NF-kappa B complexes differing in their larger subunit bind the E-selectin promoter kappa B element. Nucleic Acids Res 1993; 21: 3711-7.

30 Pacher P, Szabo C. Role of poly(ADP-ribose) polymerase-1 activation in the pathogenesis of diabetic complications: endothelial dysfunction, as a common underlying theme. Antioxid Redox Signal 2005; 7: 1568-80.

31 lademarco MF, McQuillan JJ, Rosen GD, Dean DC. Characterization of the promoter for vascular cell adhesion molecule-1 (VCAM-1). J Biol Chem 1992; 267: 16323-9.

32 Haubner F, Lehle K, Munzel D, Schmid C, Birnbaum DE, Preuner JG. Hyperglycemia increases the levels of vascular cellular adhesion molecule-1 and monocyte-chemoattractant-protein-1 in the diabetic endothelial cell. Biochem Biophys Res Commun 2007; 360: 560-5.

33 Barthel SR, Johansson MW, McNamee DM, Mosher DF. Roles of integrin activation in eosinophil function and the eosinophilic inflammation of asthma. J Leukoc Biol 2008; 83: 1-12.

34 Liu HT, He JL, Li WM, Yang Z, Wang YX, Yin J, et al. Geniposide inhibits interleukin- 6 and interleukin- 8 production in lipopolysaccharideinduced human umbilical vein endothelial cells by blocking p38 and ERK1/2 signaling pathways. Inflamm Res 2010; 59: 451-61.

35 Guha M, Bai W, Nadler JL, Natarajan R. Molecular mechanisms of 
tumor necrosis factor alpha gene expression in monocytic cells via hyperglycemia-induced oxidant stress-dependent and -independent pathways. J Biol Chem 2000; 275: 17728-39.

36 Hoefen RJ, Berk BC. The role of MAP kinases in endothelial activation. Vascul Pharmacol 2002; 38: 271-73.

37 Liu J, Yin F, Zheng X, Jing J, Hu Y. Geniposide, a novel agonist for GLP-1 receptor, prevents PC12 cells from oxidative damage via MAP kinase pathway. Neurochem Int 2007; 51: 361-9.

38 Peng $\mathrm{CH}$, Huang $\mathrm{CN}$, Hsu SP, Wang CJ. Penta-acetyl geniposideinduced apoptosis involving transcription of NGF/p75 via MAPK- mediated AP-1 activation in C6 glioma cells. Toxicology 2007; 238: 130-9.

39 Shimada H, Rajagopalan LE. RHO kinase-2 activation in human endothelial cells drives LPA-mediated expression of cell adhesion molecules via NF-\{kappa\}B p65. J Biol Chem 2010; 285: 1253642.

40 Manna SK, Mukhopadhyay A, Aggarwal BB. Leflunomide suppresses TNF-induced cellular responses: effects on NF-kappa B, activator protein-1, c-Jun $\mathrm{N}$-terminal protein kinase, and apoptosis. J Immunol 2000; 165: 5962-9. 